Supporting Information for

\title{
Effect of Anions on the Changes in the Structure and Adsorption Mechanism of Zirconium Species at the Muscovite (001) - Water Interface
}

Ke Yuan, ${ }^{1,}$ Jacquelyn N. Bracco, ${ }^{1, \dagger}$ Moritz Schmidt, ${ }^{2}$ L. Soderholm, ${ }^{1}$ Paul Fenter, ${ }^{1}$ and Sang Soo Lee $^{1, *}$

1. Chemical Sciences and Engineering Division, Argonne National Laboratory. 9700 South Cass Avenue, Lemont, Illinois 60607, United States

2. Helmholtz-Zentrum Dresden-Rossendorf, Institute of Resource Ecology, 01328 Dresden, Germany

$\S$ Present address: Chemical Sciences Division, Oak Ridge National Laboratory, Oak Ridge, TN, USA

${ }^{\dagger}$ Present address: School of Earth and Environmental Sciences, Queens College, City University of New York, Flushing, NY, USA

* Corresponding author: phone: (630)252-6679; fax: (630)252-9570; e-mail: sslee@anl.gov

This document contains supporting information (SI) on solution composition and reaction time; particle analysis of AFM images; experimental setup for X-ray reflectivity (XR) measurements; crystal truncation rod (CTR) best-fit model analysis; resonant anomalous X-ray reflectivity (RAXR) best-fit model analysis; X-ray beam-induced changes during CTR measurements; resonant anomalous dispersion terms of aqueous $\mathrm{Zr}(\mathrm{IV})$ species; normalized XR; RAXR data; model-independent RAXR analysis results.

Number of pages: 12

Number of tables: 5

Number of figures: 8 
Table S1. Solution composition and reaction time.

\begin{tabular}{lllllll}
\hline \hline \multirow{2}{*}{ samples } & background & \multirow{2}{*}{$\begin{array}{l}\text { electrolytes } \\
\end{array}$} & & & ionic strength & \multicolumn{4}{l}{ reaction time (h) } \\
\cline { 5 - 7 } & & & $\mathrm{AFM}^{a}$ & $\mathrm{XRF}^{a}$ & $\mathrm{XR}^{a}$ \\
\hline $\mathrm{Zr}-\mathrm{ClO}_{4}$ & $0.1 \mathrm{M} \mathrm{NaClO}_{4}$ & 3 & 0.1 & 8 & 6,50 & 7 \\
$\mathrm{Zr}-\mathrm{Cl}$ & $0.1 \mathrm{M} \mathrm{NaCl}$ & 3 & 0.1 & 7 & 6,50 & 6 \\
$\mathrm{Zr}-\mathrm{SO}_{4}$ & $0.04 \mathrm{M} \mathrm{Na}_{2} \mathrm{SO}_{4}$ & 3 & 0.1 & 6 & $6,7,28,50$ & 6 \\
$\mathrm{Zr}-\mathrm{HPO}_{4}$ & $0.045 \mathrm{M} \mathrm{Na}_{2} \mathrm{HPO}_{4}$ & 3 & 0.1 & 6.5 & 6,50 & 8
\end{tabular}

${ }^{a}$ AFM: atomic force microscopy, XRF: X-ray fluorescence, XR: X-ray reflectivity

Table S2. Particle analysis results of AFM images.

\begin{tabular}{lccccc}
\hline \hline samples & $\begin{array}{c}\text { number of } \\
\text { particles }\end{array}$ & $\begin{array}{c}\text { areal coverage } \\
(\%)\end{array}$ & $\begin{array}{c}\text { median height } \\
(\mathrm{nm})\end{array}$ & mean AR & $\mathrm{AR}^{a}>0.75(\%)$ \\
\hline $\mathrm{Zr}-\mathrm{ClO}_{4}$ & 400 & 7.9 & 4.4 & 0.5 & 14 \\
$\mathrm{Zr}-\mathrm{Cl}$ & 452 & 10.4 & 4.1 & 0.6 & 21 \\
$\mathrm{Zr}-\mathrm{SO}_{4}$ & 2124 & 7.0 & 9.7 & 0.5 & 12 \\
$\mathrm{Zr}-\mathrm{HPO}_{4}$ & 80 & 0.5 & 1.6 & 0.7 & 36 \\
\hline
\end{tabular}

${ }^{a}$ AR: Aspect ratio (short width/long width)

Table S3. Experimental setup for X-ray reflectivity measurements at the mica (001) - Zr solution interfaces.

\begin{tabular}{lllllll}
\hline \hline samples & beamline & $\begin{array}{l}\text { beam size }^{a} \\
\left(\mathrm{v} \times \mathrm{h}, \mathrm{mm}^{2}\right)\end{array}$ & $\begin{array}{l}\text { flux } \\
(\text { photons/sec }\end{array}$ & $\begin{array}{l}\text { photon } \\
\text { energy } \\
(\mathrm{keV})\end{array}$ & $\begin{array}{l}\text { total } \\
\text { measurement } \\
\text { time (min) }\end{array}$ & $\begin{array}{l}\text { beam } \\
\text { exposure } \\
\text { time (min) }\end{array}$ \\
\hline $\mathrm{Zr}-\mathrm{ClO}_{4}$ & $33-\mathrm{ID}-\mathrm{D}$ & $0.12 \times 1.2$ & $2 \times 10^{12}$ & 15 & 34 & 20 \\
$\mathrm{Zr}-\mathrm{Cl}$ & $12-\mathrm{ID}-\mathrm{D}$ & $0.08 \times 1.2$ & $2 \times 10^{12}$ & 21 & 90 & 20 \\
$\mathrm{Zr}-\mathrm{SO}_{4}$ & 33-ID-D & $0.10 \times 0.8$ & $1 \times 10^{12}$ & 16 & 31 & 20 \\
$\mathrm{Zr}_{-} \mathrm{HPO}_{4}$ & 6-ID-B & $0.06 \times 0.7$ & $6 \times 10^{11}$ & 16 & 47 & 24 \\
\hline
\end{tabular}

${ }^{a}$ defined by slits located before the sample.

${ }^{b}$ measured at the sample location. 
Table S4. Fitting parameters of the CTR data at the mica (001) - Zr solution interface.

\begin{tabular}{|c|c|c|c|c|}
\hline samples & $\mathrm{Zr}-\mathrm{ClO}_{4}$ & $\mathrm{Zr}-\mathrm{Cl}$ & $\mathrm{Zr}-\mathrm{SO}_{4}$ & $\mathrm{Zr}-\mathrm{HPO}_{4}$ \\
\hline $\begin{array}{c}\chi^{2} \\
\text { (R-factor) }\end{array}$ & $\begin{array}{c}3.49 \\
(0.051)\end{array}$ & $\begin{array}{c}3.16 \\
(0.087)\end{array}$ & $\begin{array}{c}2.06 \\
(0.039)\end{array}$ & $\begin{array}{c}1.59 \\
(0.056)\end{array}$ \\
\hline $\begin{array}{c}\text { adsorbed } \\
z_{1} \\
o_{1} \\
u_{1}\end{array}$ & & & $\begin{array}{c}0.68 \pm 0.06 \\
0.32 \pm 0.04 \\
0.20 \text { (f) }\end{array}$ & $\begin{array}{c}0.75 \pm 0.04 \\
0.50 \pm 0.05 \\
0.20 \text { (f) }\end{array}$ \\
\hline $\begin{array}{l}z_{2} \\
o_{2} \\
u_{2}\end{array}$ & $\begin{array}{l}3.04 \pm 0.02 \\
5.16 \pm 0.35 \\
0.73 \pm 0.02\end{array}$ & $\begin{array}{l}3.13 \pm 0.03 \\
6.08 \pm 0.24 \\
0.79 \pm 0.06\end{array}$ & $\begin{array}{l}2.80 \pm 0.02 \\
7.20 \pm 0.12 \\
0.95 \pm 0.02\end{array}$ & $\begin{array}{l}2.84 \pm 0.02 \\
7.74 \pm 0.15 \\
0.91 \pm 0.02\end{array}$ \\
\hline $\begin{array}{l}z_{3} \\
o_{3} \\
u_{3}\end{array}$ & $\begin{array}{c}6.42 \pm 0.05 \\
10.18 \pm 0.58 \\
1.51 \pm 0.12\end{array}$ & $\begin{array}{l}6.47 \pm 0.05 \\
7.73 \pm 0.40 \\
0.93 \pm 0.07\end{array}$ & $\begin{array}{l}6.11 \pm 0.04 \\
4.06 \pm 0.20 \\
0.95 \pm 0.04\end{array}$ & $\begin{array}{l}6.11 \pm 0.04 \\
4.67 \pm 0.22 \\
0.94 \pm 0.05\end{array}$ \\
\hline $\begin{array}{l}z_{4} \\
o_{4} \\
u_{4}\end{array}$ & $\begin{array}{l}9.57 \pm 0.04 \\
3.74 \pm 0.30 \\
0.76 \pm 0.04\end{array}$ & $\begin{array}{l}9.45 \pm 0.09 \\
6.82 \pm 0.86 \\
0.98 \pm 0.08\end{array}$ & & \\
\hline $\begin{array}{l}z_{5} \\
o_{5} \\
u_{5}\end{array}$ & $\begin{array}{c}13.21 \pm 0.10 \\
13.63 \pm 0.61 \\
2.47 \pm 0.13\end{array}$ & $\begin{array}{c}13.27 \pm 0.22 \\
10.06 \pm 1.33 \\
1.90 \pm 0.28\end{array}$ & & \\
\hline $\begin{array}{c}\text { layered } w \\
z_{\mathrm{W} 0} \\
u_{\mathrm{W} 0} \\
d_{\mathrm{W}} \\
u_{\mathrm{bar}}\end{array}$ & $\begin{array}{l}\text { nodel } \\
21.32 \pm 0.33 \\
1.16 \pm 0.13 \\
1.00(\mathrm{f}) \\
1.00(\mathrm{f})\end{array}$ & $\begin{array}{c}21.07 \pm 0.60 \\
1.20 \pm 0.47 \\
1.00(\mathrm{f}) \\
1.00(\mathrm{f})\end{array}$ & $\begin{array}{l}9.28 \pm 0.07 \\
1.57 \pm 0.07 \\
3.78 \pm 0.12 \\
0.76 \pm 0.09\end{array}$ & $\begin{array}{l}9.46 \pm 0.06 \\
1.24 \pm 0.05 \\
3.54 \pm 0.08 \\
0.75 \pm 0.04\end{array}$ \\
\hline
\end{tabular}

$\chi^{2}=\left[\Sigma_{\mathrm{k}}\left(I_{\mathrm{k}}-I_{\text {calc, } \mathrm{k}}\right)^{2} / \sigma_{\mathrm{k}}{ }^{2}\right] /\left(N-N_{\mathrm{p}}\right)$ and R-factor $\left(=\Sigma_{\mathrm{k}} \mid\left(I_{\mathrm{k}}-I_{\text {calc, } \mathrm{k}}\right) / I_{\mathrm{k}} / / N\right)$ where $N$ and $N_{\mathrm{p}}$ are the numbers of data points and parameters used in a model fit, respectively, $I_{\mathrm{k}}$ and $I_{\text {calc, } \mathrm{k}}$ are the measured and calculated reflected intensities, respectively, and $\sigma_{\mathrm{k}}$ is the uncertainty of the $\mathrm{k}^{\text {th }}$ data point.

$z_{\mathrm{j}}, o_{\mathrm{j}}$, and $u_{\mathrm{j}}$ : height $(\AA)$ from the mica (001) surface, occupancy, and rms distribution width $(\AA)$ of aqueous species adsorbed on the mica surface. The occupancy is expressed with water-equivalent electron density $\left(W_{\mathrm{eq}}\right)$ per $1 \AA$ in height. ${ }^{\mathrm{S} 1}$ As a reference, the $W_{\text {eq }}$ of bulk water is 1.54 on the mica (001) surface at $25^{\circ} \mathrm{C}$.

f: fixed during fit

$z_{\mathrm{w} 0}$ and $u_{\mathrm{w} 0}$ : the height $(\AA)$ and vertical rms distribution width $(\AA)$ of the water layer closest the mica surface within the layered water model, and $d_{\mathrm{w}}$ : the distance between two adjacent water layers. ${ }^{\mathrm{S} 2}$ The $u$ parameters for the successive layers were calculated as $u_{\mathrm{w} k}=\left[u_{\mathrm{w} 0} 0^{2}+k\left(u_{\mathrm{bar}}\right)^{2}\right]$ where $k$ is an integer. 
Table S5. Fitting parameters for the RAXR data describing the Zr distribution at the mica (001) $\mathrm{Zr}$ solution interface.

\begin{tabular}{|c|c|c|c|c|}
\hline samples & $\mathrm{Zr}-\mathrm{ClO}_{4}$ & $\mathrm{Zr}-\mathrm{Cl}$ & $\mathrm{Zr}-\mathrm{SO}_{4}$ & $\mathrm{Zr}-\mathrm{HPO}_{4}$ \\
\hline $\begin{array}{c}\chi^{2} \\
\text { (R-factor) }\end{array}$ & $\begin{array}{c}1.69 \\
(0.012)\end{array}$ & $\begin{array}{c}2.81 \\
(0.013)\end{array}$ & $\begin{array}{c}1.07 \\
(0.004)\end{array}$ & $\begin{array}{c}1.28 \\
(0.005)\end{array}$ \\
\hline$z_{, \mathrm{Zr} 1}$ & $6.37 \pm 0.15$ & $6.80 \pm 0.24$ & $6.59(f)$ & $6.59(\mathrm{f})$ \\
\hline$o_{, \mathrm{Zr} 1}$ & $0.12 \pm 0.02$ & $0.06 \pm 0.02$ & $0.03 \pm 0.01^{a}$ & $0.00 \pm 0.01^{a}$ \\
\hline$u_{, \mathrm{Zr} 1}$ & $0.4(\mathrm{f})$ & $0.4(f)$ & $0.4(\mathrm{f})$ & $0.4(f)$ \\
\hline$z_{, \mathrm{Zr} 2}$ & $8.23 \pm 0.11$ & $8.75 \pm 0.17$ & $8.49(\mathrm{f})$ & 8.49 (f) \\
\hline$o_{, \mathrm{Zr} 2}$ & $0.89 \pm 0.06$ & $1.30 \pm 0.07$ & $0.00 \pm 0.01^{a}$ & $0.01 \pm 0.02^{a}$ \\
\hline$u_{, \mathrm{Zr} 2}$ & $1.85 \pm 0.10$ & $2.94 \pm 0.14$ & $2.39(\mathrm{f})$ & $2.39(\mathrm{f})$ \\
\hline$z, \mathrm{Zr} 3$ & $12.67 \pm 0.18$ & $15.08 \pm 0.82$ & $13.88(f)$ & $13.88(\mathrm{f})$ \\
\hline$o, \mathrm{Zr} 3$ & $1.11 \pm 0.04$ & $0.23 \pm 0.05$ & $0.02 \pm 0.01^{a}$ & $0.00 \pm 0.02^{a}$ \\
\hline$u_{, \mathrm{Zr} 3}$ & $3.0(\mathrm{f})$ & $3.0(\mathrm{f})$ & $3.0(\mathrm{f})$ & $3.0(f)$ \\
\hline
\end{tabular}

$z, \mathrm{Zrj}, o_{\mathrm{Zr}}$, and $u_{\text {,Zrj }}$ height $(\AA)$ from the mica (001) surface, occupancy ( $\mathrm{Zr}$ atom/ $\left./ A_{\mathrm{UC}}\right)$, and rms distribution width $(\AA)$ of the $\mathrm{j}^{\text {th }} \mathrm{Zr}$ peak.

f: fixed during fit

${ }^{a}$ determined with fixed height and rms width on the basis of the average values from the best-fit models for the $\mathrm{Zr}-\mathrm{ClO}_{4}$ and $\mathrm{Zr}-\mathrm{Cl}$. 


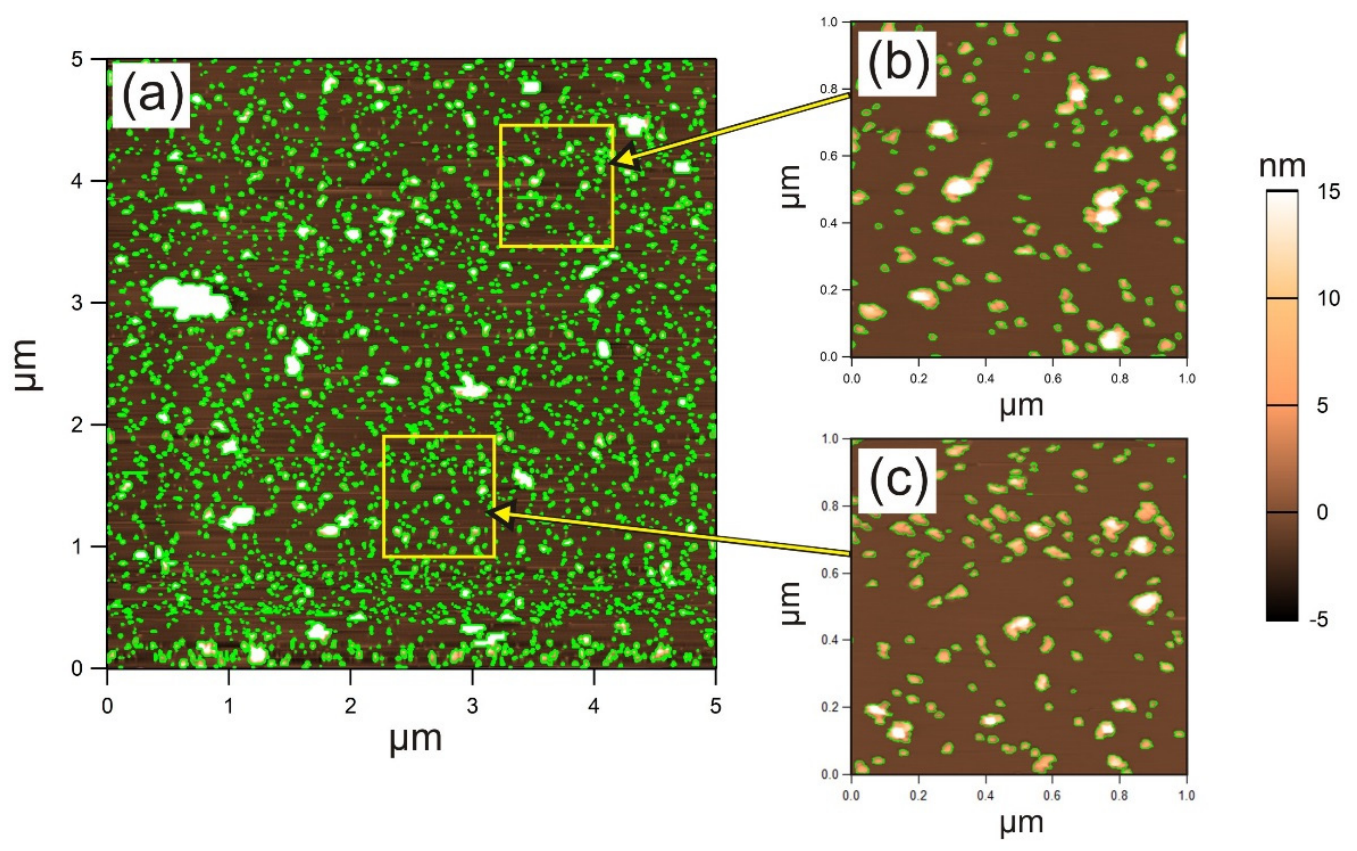

Figure S1. Boundaries of nanoparticles determined by the particle analysis tool with the Asylum Research software on the mica (001) reacted in $0.1 \mathrm{mM} \mathrm{Zr}(\mathrm{IV})$ in $0.1 \mathrm{M} \mathrm{NaCl}$ background electrolyte for $7 \mathrm{~h}(\mathrm{a}: 5 \mu \mathrm{m} \times 5 \mu \mathrm{m}$ and b and c: $1 \mu \mathrm{m} \times 1 \mu \mathrm{m})$.
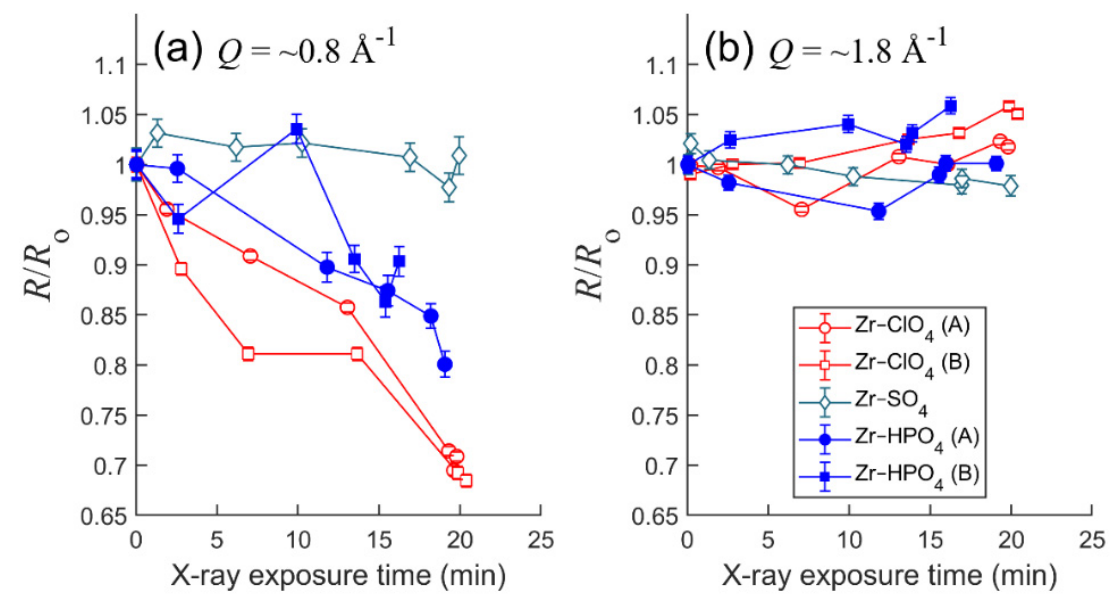

Figure S2. Changes in X-ray reflectivity from the mica (001) - Zr solution interface as a function of beam exposure time during CTR measurements at two reference $Q$ values. 


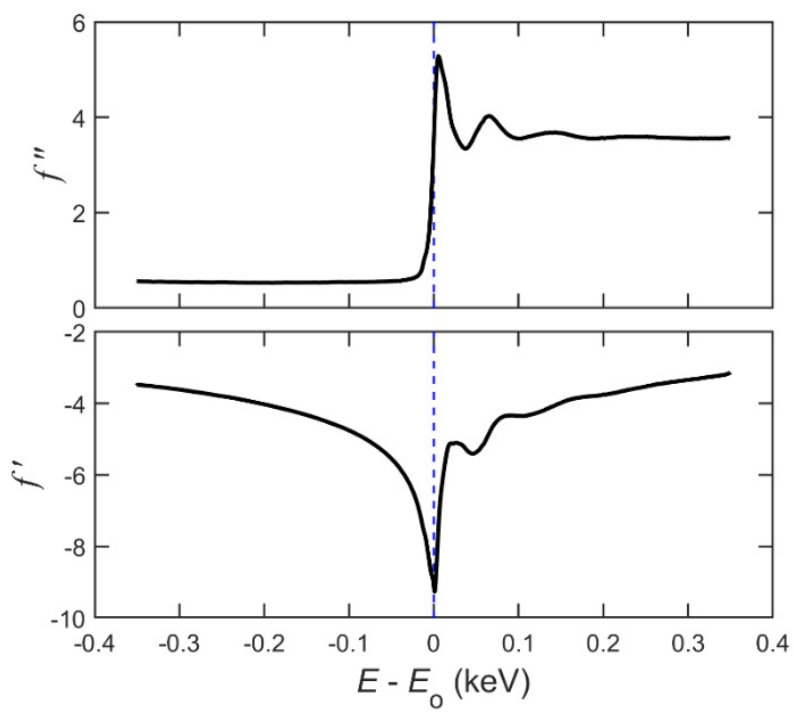

Figure S3. Resonant anomalous dispersion terms $\left(f^{\prime}\right.$ and $\left.f^{\prime \prime}\right)$ for $\operatorname{Zr}(\mathrm{IV})$ aqueous species. The spectra were determined on the basis of the X-ray absorption near-edge structure of Zr measured near its $\mathrm{K}$ X-ray absorption edge energy $\left(E_{\mathrm{o}} \approx 18.0 \mathrm{keV}\right)$ in a $0.1 \mathrm{M} \mathrm{ZrCl} 4$ solution in transmission mode accompanied with the difference Kramers-Kronig transform. ${ }^{\mathrm{S} 3}$ 


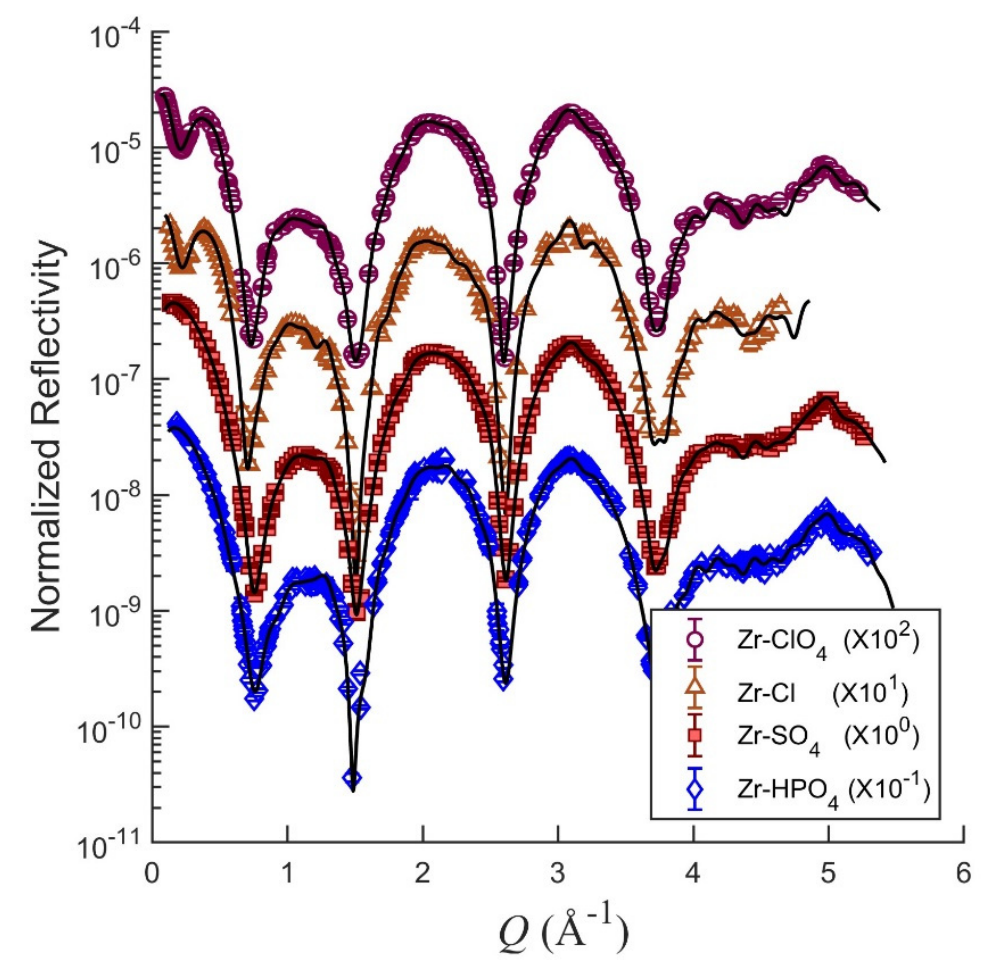

Figure S4. Normalized X-ray reflectivity at the mica $(001)-\mathrm{Zr}$ solution interface. The normalized reflectivity $\left(R_{\text {norm}}\right)$ is derived by dividing the reflectivity $(R)$ by the generic CTR shape, $1 /[Q \sin (Q d / 4)]^{2}$, where $Q$ is the momentum transfer perpendicular to the (001) plane and $d(\approx 19.96 \AA)$ is the $(001)$ lattice spacing. The datasets were scaled vertically for clarity using the multiplicative factors given in parentheses after the sample names. 


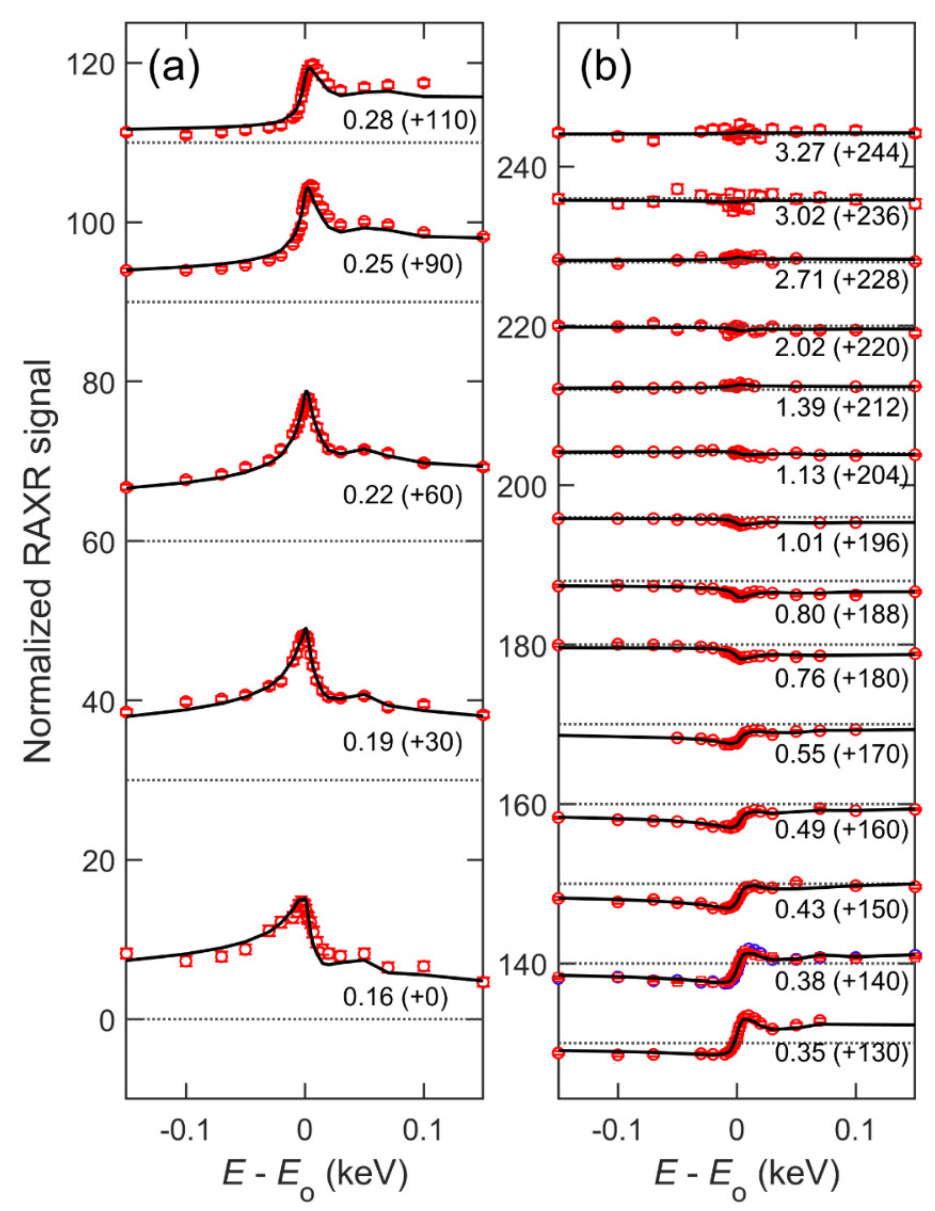

Figure S5. Resonant anomalous X-ray reflectivity (RAXR) for the $\mathrm{Zr}-\mathrm{ClO}_{4} \mathrm{Data}$. The data measured at lower $Q\left(<0.3 \AA^{-1}\right)$ are listed in (a) and those at higher $Q$ are listed in (b). The symbols (red or blue) represent the measured data and the solid curves are calculated from the best-fit model (Table S5). The spectra are normalized based on the resonant amplitude normalization method $\left(\left|F_{\text {tot }}(Q, E)\right|^{2}-\left|F_{\mathrm{NR}}(Q)\right|^{2}\right) /\left(2\left|F_{\mathrm{NR}}(Q)\right|\right)$, where $F_{\text {tot }}$ and $F_{\mathrm{NR}}$ are total and nonresonant structure factors, respectively. ${ }^{\mathrm{S} 4}$ Each spectrum is labeled with the $Q$ value $\left(\AA^{-1}\right)$ where the spectrum was measured and the vertical offset in the parentheses. 


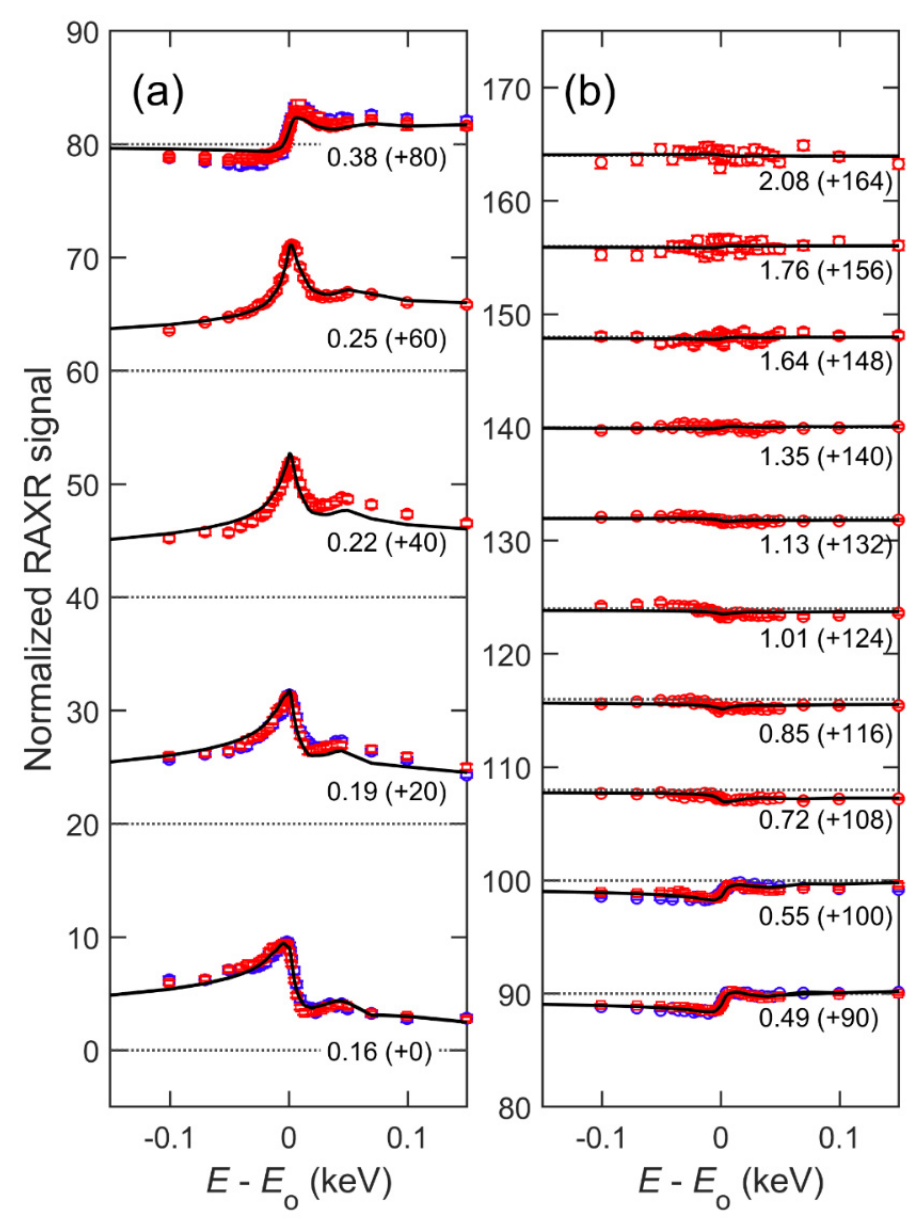

Figure S6. Resonant anomalous X-ray reflectivity (RAXR) for the $\mathrm{Zr}-\mathrm{Cl}$ data. The data measured at $Q<0.4 \AA^{-1}$ are shown in (a) and those at $Q>0.4 \AA^{-1}$ are shown in (b). The symbols represent the measured data. Duplicates were measured at different areas of the same sample for several $Q$ values as shown in red and blue symbols. The solid curves are calculated from the best-fit model (Table S5). The spectra are normalized based on the resonant amplitude normalization method $\left(\left|F_{\text {tot }}(Q, E)\right|^{2}-\left|F_{\mathrm{NR}}(Q)\right|^{2}\right) /\left(2\left|F_{\mathrm{NR}}(Q)\right|\right)$, where $F_{\text {tot }}$ and $F_{\mathrm{NR}}$ are total and nonresonant structure factors, respectively. ${ }^{\mathrm{S} 4}$ Each spectrum is labeled with the $Q$ value $\left(\AA^{-1}\right)$ where the spectrum was measured and the vertical offset in the parentheses. 

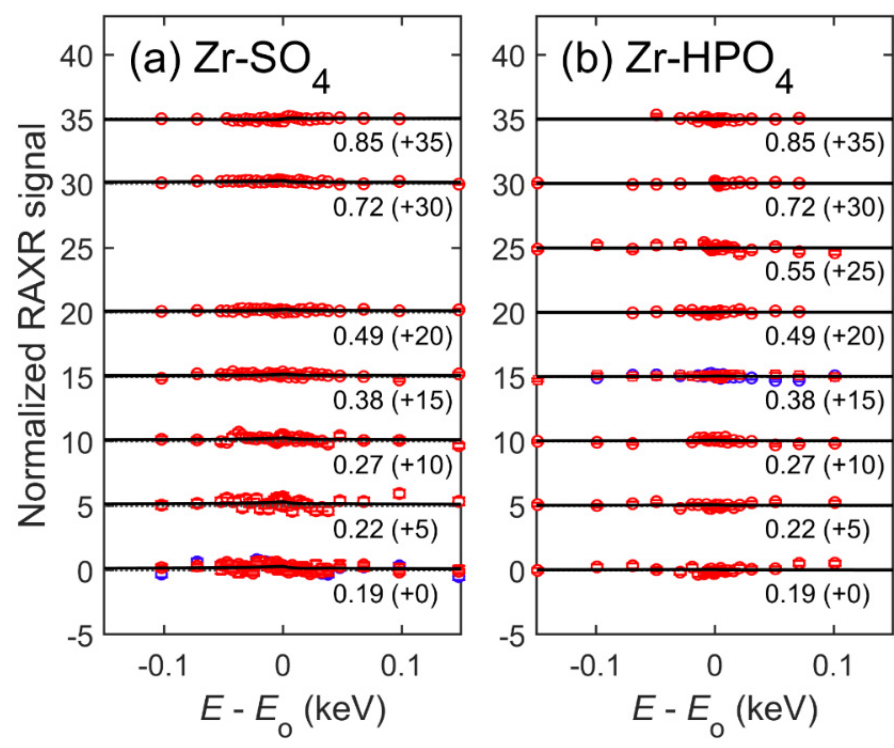

Figure S7. Resonant anomalous X-ray reflectivity (RAXR) for (a) $\mathrm{Zr}-\mathrm{SO}_{4}$ and (b) $\mathrm{Zr}-\mathrm{HPO}_{4}$ data. The symbols represent the measured data. The solid curves are calculated from the best-fit model (Table S5). The spectra are normalized based on the resonant amplitude normalization method $\left(\left|F_{\text {tot }}(Q, E)\right|^{2}-\left|F_{\mathrm{NR}}(Q)\right|^{2}\right) /\left(2\left|F_{\mathrm{NR}}(Q)\right|\right)$, where $F_{\text {tot }}$ and $F_{\mathrm{NR}}$ are total and non-resonant structure factors, respectively. ${ }^{\mathrm{S} 4}$ Each spectrum is labeled with the $Q$ value $\left(\AA^{-1}\right)$ where the spectrum was measured and the vertical offset in the parentheses. Duplicates measured at different areas of the same sample are shown in red and blue symbols for $Q=0.19 \AA^{-1}$ for $\mathrm{Zr}-$ $\mathrm{SO}_{4}$ and $0.38 \AA^{-1}$ for $\mathrm{Zr}-\mathrm{HPO}_{4}$. 

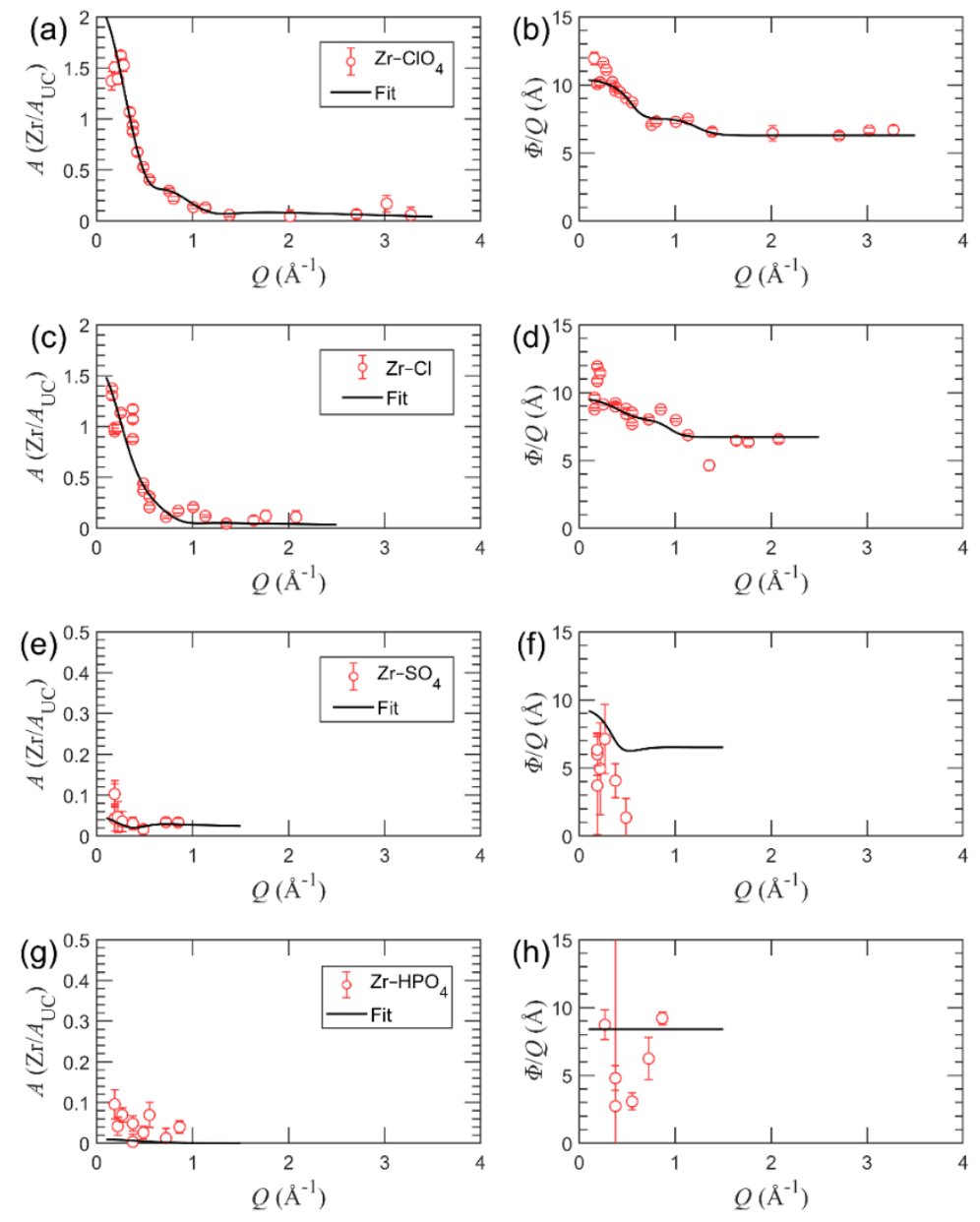

Figure S8. Variation of the partial structure factor amplitude, $A$, and phase, $\Phi / Q$ of $\operatorname{Zr}(\mathrm{IV})$ distributed at the mica (001) surface for $\mathrm{Zr}-\mathrm{ClO}_{4}$ (a and b), $\mathrm{Zr}-\mathrm{Cl}$ (c and d), $\mathrm{Zr}-\mathrm{SO}_{4}$ (e and f), and $\mathrm{Zr}-\mathrm{HPO}_{4}(\mathrm{~g}$ and $\mathrm{h}$ ), respectively. The data points were determined with the modelindependent analysis ${ }^{\mathrm{S} 5}$ and the solid lines were calculated based on the best-fit models (Table S5). Note the difference in the $A$ range between a and c vs. e and $\mathrm{g}$. 


\section{SI References:}

S1. $\quad$ Lee, S. S.; Nagy, K. L.; Fenter, P., Distribution of barium and fulvic acid at the micasolution interface using in-situ X-ray reflectivity. Geochim. Cosmochim. Acta 2007, 71, 5763-5781.

S2. $\quad$ Schlegel, M. L.; Nagy, K. L.; Fenter, P.; Sturchio, N. C., Structures of quartz (100)- and (101)-water interfaces determined by X-ray reflectivity and atomic force microscopy of natural growth surfaces. Geochim. Cosmochim. Acta 2002, 66, 3037-3054.

S3. Cross, J. O.; Newville, M.; Rehr, J. J.; Sorensen, L. B.; Bouldin, C. E.; Watson, G.; Gouder, T.; Lander, G. H.; Bell, M. I., Inclusion of local structure effects in theoretical $\mathrm{X}$-ray resonant scattering amplitudes using ab initio X-ray-absorption spectra calculations. Phys. Rev. B 1998, 58, 11215-11225.

S4. Lee, S. S.; Nagy, K. L.; Park, C.; Fenter, P., Enhanced uptake and modified distribution of mercury(II) by fulvic acid on the muscovite (001) surface. Environ. Sci. Technol. 2009, 43, 5295-5300.

S5. Park, C.; Fenter, P. A., Phasing of resonant anomalous X-ray reflectivity spectra and direct Fourier synthesis of element-specific partial structures at buried interfaces. J. Appl. Crystallogr. 2007, 40, 290-301. 